\title{
Successful operative management of an upper lumbar spinal canal stenosis resulting in multilevel lower nerve root radiculopathy
}

\author{
Shearwood McClelland 3 ${ }^{\text {rd }}$, Stefan S. Kim \\ Department of Neurosurgery, Lahey Clinic, Burlington, Massachusetts, United States
}

\begin{abstract}
Lumbar stenosis is a common disorder, usually characterized clinically by neurogenic claudication with or without lumbar/sacral radiculopathy corresponding to the level of stenosis. We present a case of lumbar stenosis manifesting as a multilevel radiculopathy inferior to the nerve roots at the level of the stenosis. A 55-year-old gentleman presented with bilateral lower extremity pain with neurogenic claudication in an $\mathrm{L}_{5} / \mathrm{S}_{1}$ distribution (posterior thigh, calf, into the foot) concomitant with dorsiflexion and plantarflexion weakness. Imaging revealed grade I spondylolisthesis of $\mathrm{L}_{3}$ on $\mathrm{L}_{4}$ with severe spinal canal stenosis at $\mathrm{L}_{3}-\mathrm{L}_{4}$, mild left $\mathrm{L}_{4}-\mathrm{L}_{5}$ disc herniation, no stenosis at $\mathrm{L}_{5}-\mathrm{S}_{1}$, and no instability. EMG revealed active and chronic $\mathrm{L}_{5}$ and $\mathrm{S}_{1}$ radiculopathy. The patient underwent bilateral $\mathrm{L}_{3}-\mathrm{L}_{4}$ hemilaminotomy with left L4-L5 microdiscectomy for treatment of his L3-L4 stenosis. Postoperatively, he exhibited significant improvement in dorsiflexion and plantarflexion. The L5-S1 level was not involved in the operative decompression. Patients with radiculopathy and normal imaging at the level corresponding to the radiculopathy should not be ruled out for operative intervention should they have imaging evidence of lumbar stenosis superior to the expected affected level.
\end{abstract}

Key words: Neurogenic claudication, radiculopathy, surgical decompression, upper lumbar stenosis

\section{Introduction}

The condition of lumbar stenosis results from a formation of a neural arch that is abnormally small in diameter, and triangular rather than round in shape. ${ }^{[1,2]}$ Developmental narrowing of the lumbar vertebral canal has been known to cause radicular syndrome, with symptoms correlating to the severity and level of the stenosis on imaging; compression in the L3-L4 space affects the L4 nerve root, while compression in the L5-S1 space affects the S1 nerve root. ${ }^{[3,4]}$

Previous studies have indicated that in rare instances, the level of lumbar stenosis on imaging does not correlate

\begin{tabular}{|l|l|}
\hline \multicolumn{2}{|c|}{ Access this article online } \\
\hline Quick Response Code: & Website: \\
\hline & www.ruralneuropractice.com \\
\cline { 2 - 2 } & \\
\hline
\end{tabular}

with the level of symptomatology. ${ }^{[4,5]}$ We report a patient who presented with L5 and S1 radiculopathy in the setting of severe L3-L4 stenosis.

\section{Case Report}

A 55-year-old gentleman presented with a several month history of bilateral lower extremity leg pain concomitant with numbness and weakness in both of his lower extremities. These symptoms were not initiated by a precipitating event. He complained of pain radiating down into his posterior thigh, calf and into the foot bilaterally. Social history was pertinent for a 40-pack-year smoking history and an occupation of a heavy machine operator. His pain symptoms were minimal with sitting or lying down, but pronounced with prolonged standing and walking.

On examination, his motor strength was full except for dorsiflexion and plantar flexion, which were $3 / 5$ bilaterally. He also had difficulty performing toe and heel walking. Deep tendon reflexes were $1^{+}$in patellas and absent in his ankles; he also had sensory deficits in his foot.

Address for correspondence:

Dr. Shearwood McClelland 3 ${ }^{\text {rd }}$, Department of Neurosurgery, Lahey Clinic, 41 Mall Road, Burlington, Massachusetts 01805 , United States.

E-mail: drwood@post.harvard.edu 
Lumbar spine MRI revealed evidence of grade I spondylolisthesis of L3 and L4 resulting in severe spinal canal stenosis, with no stenosis at L5-S1 [Figure 1]. Lumbar flexion and extension imaging demonstrated no evidence of increased subluxation despite the grade I spondylolisthesis. EMG revealed evidence of active and chronic L5 and S1 radiculopathy, with active denervation and moderate chronic denervation in the medial gastrocnemius muscles bilaterally (left worse than right).

Given the patient's clinical and imaging findings, which did not demonstrate significant instability, the decision was made to perform bilateral hemilaminotomy to decompress L3-L4. Due to his smoking history, he was not offered a fusion; however, given his motor weakness, it was believed that decompression would offer him the best chance of regaining full dorsiflexion and plantarflexion function.

He was subsequently taken to the operating room, where bilateral partial L3-L4 hemilaminotomy was performed. Due to a small left L4-L5 disc hernation on MRI [Figure 1b], a left L4-L5 microdiscectomy was performed as well. There was no operative involvement at L5-S1, and no spinous processes were taken in order to avoid disruption of his posterior tension band. Postoperatively, the patient regained full strength in dorsiflexion and plantarflexion bilaterally, and noted marked improvement in his preoperative symptomatology. This was consistent with the decompression visualized on postoperative MRI [Figure 2].

\section{Discussion}

This case represents a rare instance of upper lumbar spinal canal stenosis manifesting with lower nerve root pathology. The first report of such an instance occurred in 1998, involving an L5 radiculopathy secondary to L1-L2 and L2-L3 lumbar stenosis. ${ }^{[5]}$ A recent study, examining eight patients with this phenomenon, found that L5 was involved in six cases, while S1 was involved in the remaining two cases; in all eight cases, operative decompression improved symptoms. ${ }^{[4]}$ Additional reports have demonstrated L5 radiculopathy secondary to upper lumbar disc herniation as opposed to stenosis. ${ }^{[6-8]}$

Of the nine previous stenosis cases reported, seven involved radiculopathy at L5 and two involved S1 [Table 1]. This case represents the first report of multilevel radiculopathy secondary to upper lumbar stenosis, with only the third instance of $\mathrm{S} 1$ radiculopathy from upper lumbar stenosis to be reported. In seven of the previous nine cases $(77.8 \%)$, fusion rather than laminectomy/laminotomy was performed [Table 1]. However, in this patient, given his smoking history, the potential long-term downside of performing a fusion led to the decision to perform decompression without fusion. Furthermore, he demonstrated no instability
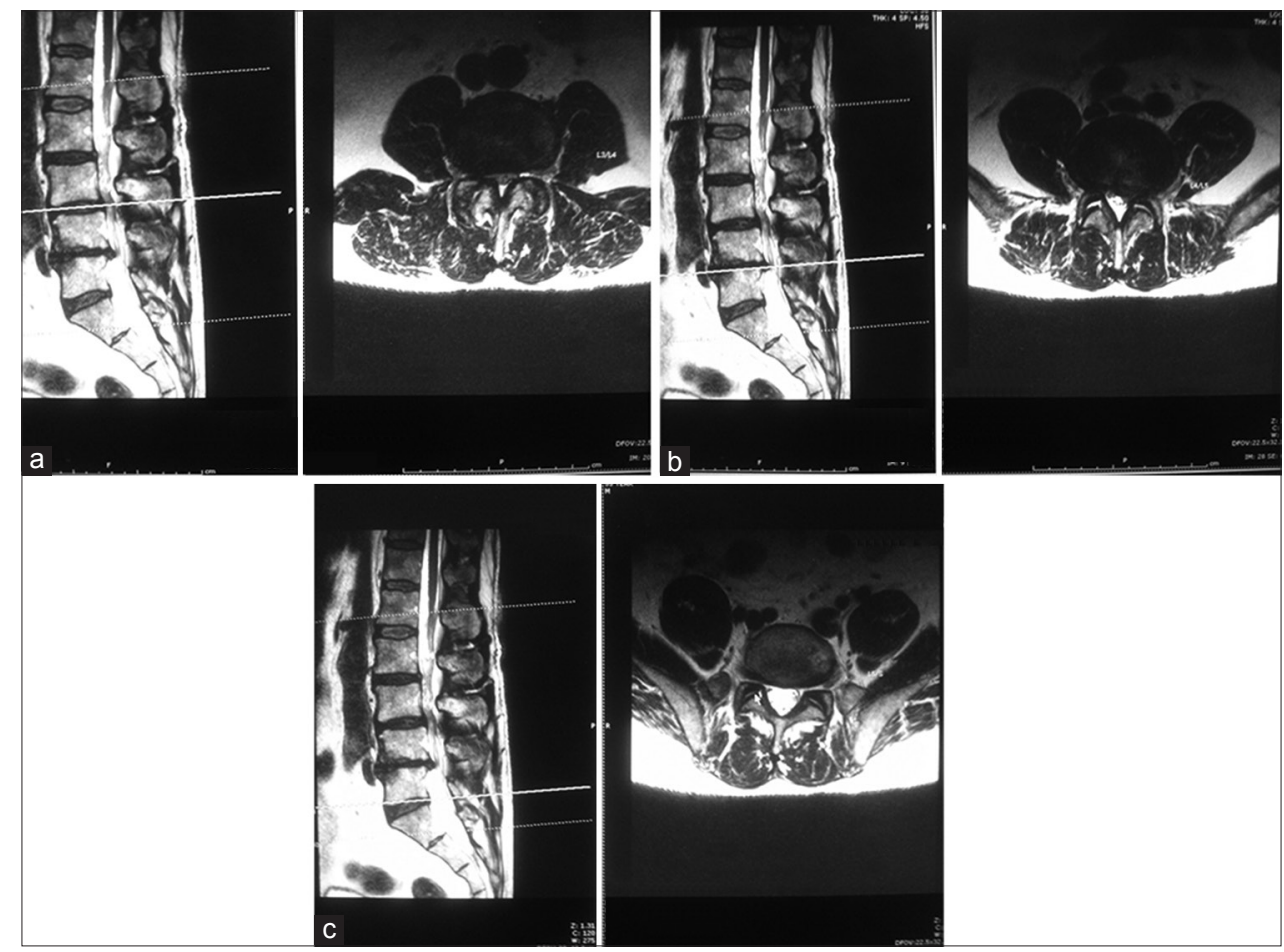

Figure 1: Sagittal and axial T2-weighted preoperative MR imaging of this patient's lumbar spine. (a) L3-L4 level, (b) L4-L5 level, (c) L5-S1 level 
Table 1: Literature review of reported cases of upper lumbar spinal stenosis manifesting as lower nerve root radiculopathy

\begin{tabular}{|c|c|c|c|c|c|c|c|c|c|}
\hline Number & $\begin{array}{c}\text { Year } \\
\text { reported }\end{array}$ & Age & Gender & $\begin{array}{l}\text { Level of } \\
\text { stenosis }\end{array}$ & Spondylolisthesis & $\begin{array}{c}\text { Neurologic } \\
\text { disturbance }\end{array}$ & $\begin{array}{l}\text { Side of } \\
\text { disturbance }\end{array}$ & $\begin{array}{l}\text { Motor } \\
\text { deficit }\end{array}$ & Surgical method \\
\hline 1 & 1998 & 69 & M & L1-L2, L2-L3 & No & L5 & Bilateral & EHL, TA & $\begin{array}{l}\text { Laminectomy with } \\
\text { parital facetectomy }\end{array}$ \\
\hline 2 & 2012 & 48 & $\mathrm{~F}$ & L3-L4 & Yes & L5 & Bilateral & $\mathrm{EHL}$ & ALIF \\
\hline 3 & 2012 & 46 & M & L2-L3 & No & L5 & Bilateral & None & ALIF \\
\hline 4 & 2012 & 68 & $\mathrm{M}$ & L3-L4 & Yes & $\mathrm{S} 1$ & Bilateral & $\mathrm{EHL}$ & PLIF \\
\hline 5 & 2012 & 55 & $\mathrm{~F}$ & L3-L4 & Yes & L5 & Bilateral & TA, EHL & ALIF \\
\hline 6 & 2012 & 68 & M & L3-L4 & Yes & L5 & Left & None & PLIF \\
\hline 7 & 2012 & 73 & M & L3-L4 & Yes & L5 & Left & EHL & PLIF \\
\hline 8 & 2012 & 57 & M & L2-L3 & No & L5 & Left & $\mathrm{EHL}$ & Laminectomy \\
\hline 9 & 2012 & 62 & $M$ & L3-L4 & Yes & $\mathrm{S} 1$ & Bilateral & None & TLIF \\
\hline Current & 2014 & 55 & $M$ & L3-L4 & Yes & L5 and S 1 & Bilateral & EHL, TA, GC & Hemilaminotomy \\
\hline Mean & & 60.1 & & & $70 \%$ & & & $70 \%$ & \\
\hline
\end{tabular}

ALIF: Anterior lumbar interbody fusion, PLIF: Posterior lumbar interbody fusion, TLIF: Transforaminal lumbar interbody fusion, EHL: External hallucis longus,

TA: Tibialis anterior muscle, GC: Gastrocnemius muscle, M: Male, F: Female

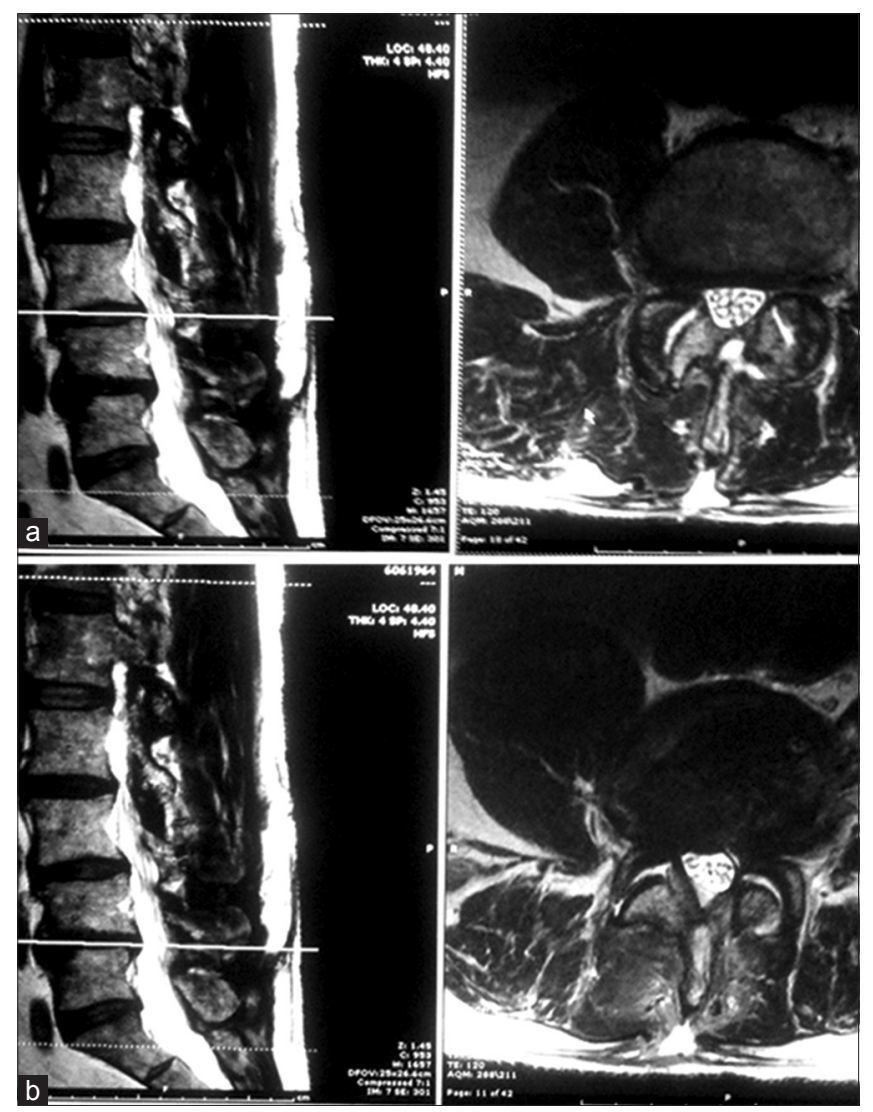

Figure 2: Sagittal and axial T2-weighted postoperative MR imaging of this patient's lumbar spine. (a) L3-L4 level, (b) L4-L5 level

on flexion/extension lumbar spine X-rays. To aid in preventing development of instability, particularly in the setting of this patient's grade I L3-L4 spondylolisthesis, laminotomy rather than full laminectomy was performed in order to preserve the posterior tension band at L3-L4. It is our hope that smoking cessation can be initiated during the postoperative period, such that should the patient eventually become unstable in the future, a fusion operation at that time would be much less likely to fail and more likely to result in a good postoperative outcome. ${ }^{[9,10]}$ Although a left L4-L5 microdiscectomy was performed, it is unlikely that this pathology was a significant contributor to his preoperative symptomatology, as it would be unable to account for the dramatic improvement in his right-sided as well as left-sided preoperative L5 and S1 symptomatology. Consequently, it is most plausible that this patient's bilateral L5 and S1 radiculopathy was secondary to the L3-L4 stenosis alone.

\section{Conclusion}

This is the first report of multilevel lower nerve root radiculopathy secondary to upper lumbar spinal canal stenosis. Our patient regained full dorsiflexion and plantarflexion motor strength following bilateral hemilaminotomy at L3-L4. This case underscores the importance of carefully examining the spinal canal levels superior to the level of radiculopathy on imaging studies, as decompression of lumbar stenosis at these levels may result in resolution of radicular symptoms.

\section{References}

1. Epstein BS, Esptein JA, Lavine L. The effect of anatomic variations in the lumbar vertebrae and spinal canal on cauda equina nerve root syndromes. Am J Roentgenol Radium Ther Nucl Med 1964;91:1055-63.

2. Binder DK, Schmidt MH, Weinstein PR. Lumbar spinal stenosis. Semin Neurol 2002;22:157-66.

3. Verbiest H. A radicular syndrome from developmental narrowing of the lumbar vertebral canal. 1954;36:230-7.

4. Eguchi Y, Ohtori S, Toyone T, Ozawa T, Yamauchi K, Yamashita M, et al. Surgical experience in cases of L5 and S1 symptoms caused by upper lumbar spinal stenosis of L2-L3 and L3-L4. J Spine 2012;1:105.

5. Hidalgo-Ovejero AM, García-Mata S, Martínez-Grande M, 
Maravi-Petri E, Izco-Cabezón T. L5 root compression caused by degenerative spinal stenosis of the L1-L2 and L2-L3 spaces. Spine (Phila Pa 1976) 1998;23:1891-4.

6. Shirado O, Matsukawa S, Kaneda K. Herniation of the disc between the first and second lumbar vertebrae with a monoradiculopathy of the fifth lumbar nerve root. J Bone Joint Surg Am 1996;78:1422-6.

7. Korovessis P, Baikousis A, Stamatakis M, Katonis P. Monoradiculopathy of the fifth lumbar nerve root due to lumbar disc herniation between lumbar one and lumbar two vertebrae. J Spinal Disord 1998;11:350-3.

8. Hidalgo-Ovejero AM, García-Mata S, Sánchez-Villares JJ, Lasanta P, Izco-Cabezón T, Martínez-Grande M. L5 root compression resulting from an L2-L3 disc herniation. Am J Orthop (Belle Mead NJ) 2003;32:392-4.
9. Glassman SD, Anagnost SC, Parker A, Burke D, Johnson JR, Dimar JR. The effect of cigarette smoking and smoking cessation on spinal fusion. Spine (Phila Pa 1976) 2000;25:2608-15.

10. Sandén B, Försth P, Michaëlsson K. Smokers show less improvement than nonsmokers two years after surgery for lumbar spinal stenosis: A study of 4555 patients from the Swedish spine register. Spine (Phila Pa 1976) 2011;36:1059-64.

How to cite this article: McClelland S, Kim SS. Successful operative management of an upper lumbar spinal canal stenosis resulting in multilevel lower nerve root radiculopathy. J Neurosci Rural Pract 2015;6:108-11.

Source of Support: Nil. Conflict of Interest: None declared. 